Glycated Haemoglobin:

\title{
Comparison between Methods Based upon 5-Hydroxymethylfurfural Determination (Colorimetric or HPLC) and Ion Exchange Chromatography $\left(\mathrm{HbA}_{1}\right)$
}

\author{
By A. Meskar, R. Le Bras, M. L'Emeillat and J.F. Ménez \\ Laboratoire de Biochimie A (Professeur L.G. Bardou), Hôpital A. Morvan, Brest Cédex, France
}

(Received August 13/October 31, 1984)

Summary: A comparison of methods, two based upon 5-hydroxymethylfurfural determination (colorimetric using a semi-automated procedure and HPLC) and ion exchange chromatography $\left(\mathrm{HbA}_{1}\right.$ using BioRad method) was performed. The influence of variables on 5-hydroxymethylfurfural determination is reported. The dialysis step appears to be essential for an accurate determination of 5-hydroxymethylfurfural released from glycated haemoglobin. The adjustment of haemoglobin concentration to an accurately known level is required for the colorimetric method, in order to achieve the same background colour absorbance. For the HPLC method this step is not necessary as 5-hydroxymethylfurfural liberation was proved to be stoichiometric. The Sep Pak C-18 cartridge purification appears to be an improvement for the accurate determination of 5 -hydroxymethylfurfural using HPLC. When the three methods were compared the overlap between normals and diabetics was found to be less, using the 5-hydroxymethylfurfural HPLC method, suggesting that this procedure, although more time consuming, seems to be more useful in the management of diabetes mellitus.

\section{Glycosyliertes Hämoglobin:}

Methodenvergleich zwischen 5-Hydroxymethylfurfuralbestimmung (Kolorimetrie bzw. HPLC) und Ionenaustauschchromatographie $\left(H b A_{1}\right)$

Zusammenfassung: Zwei Methoden auf der Grundlage der Bestimmung von 5-Hydroxymethylfurfural (halbautomatisches kolorimetrisches Verfahren bzw. HPLC) und die Ionenaustauschchromatographie $\left(\mathrm{HbA}_{1}\right.$, BioRad) wurden verglichen. Der Einfluß von Variablen auf die Bestimmung von 5-Hydroxymethylfurfural wird mitgeteilt. Der Dialyseschritt scheint für eine genaue Bestimmung von aus glycolysiertem Hämoglobin freigesetzten 5-Hydroxymethylfurfural essentiell zu sein. Zur Sicherstellung gleicher Hintergrundabsorbanz muß die Hämoglobinkonzentration bei der kolōrimetrischen Methode auf einen bekannten Wert eingestellt werden. Dies ist für die HPLC-Methode nicht erforderlich, da eine stöchiometrische Freisetzung von 5Hydroxymethylfurfural nachgewiesen wurde, jedoch scheint die Reinigung mit der Sep Pak C-18 Patrone die Genauigkeit des HPLC-Verfahrens für 5-Hydroxymethylfurfural zu verbessern. Im Methodenvergleich wurde eine geringere Überlappung von gesunden und Diabetikern bei der HPLC-Methode festgestellt, weshalb diese zwar zeitaufwendigere Methode zur Diabetes-Überwachung nützlicher ist als die kolorimetrische.

\section{Introduction}

The assay of glycated haemoglobin is a clinically useful index of long term blood glucose control in diabetes mellitus $(1-3)$. Considerable attention has therefore been paid to methods for the determination of this parameter. An extensive review of the techniques and their clinical utility was recently compiled by Mayer \& Freedman (4). 
The most frequently used techniques are based upon altered physical properties of the haemoglobin molecule or upon the release of 5-hydroxymethylfurfural from glycated haemoglobin by mild acid hydrolysis. The minicolumn cation exchange chromatographic method for $\mathrm{HbA}_{1}$ has become routine $(5-7)$. But this techniques are extremely sensitive to variations of $\mathrm{pH}$, ionic strength, temperature, column load, labile glycated haemoglobin, sample storage, lipaemia and variant haemoglobins $(8-12)$. In the colorimetric technique, 5-hydroxymethylfurfural is generally measured spectrophotometrically after reaction with thiobarbituric acid (13). Many authors (14-17) have reported that this procedure is non-stoichiometric and requires careful standardization of assay conditions, including the concentration of total haemoglobin in the assayed aliquot, in order to achieve precision and permit comparison of results. In order to obtain more reliable results some authors $(18-20)$ reported the automatization of the colorimetric procedure. Recently an HPLC determination of 5hydroxymethylfurfural without coloration was pro- posed (21), the results obtained by such a method were reported to have the advantage of specificity, accuracy and reproducibility.

The aim of the present investigation was to compare HPLC determination of 5-hydroxymethylfurfural with the colorimetric method, using a semi-automated procedure, and with the $\mathrm{HbA}_{1}$ determination on Bio-Rex 70. As the three methods were carried out on the same patients the clinical utility of these techniques will be discussed. Moreover the different steps of the hydrolysis procedure for both 5-hydroxymethylfurfural determination methods were investigated in order to attempt to simplify the procedure.

\section{Materials and Methods}

Sample collection

Venous blood samples were collected in EDTA Vacutainer tubes. Red cells were separated by centrifugation (1400 $\mathrm{g}$ for $10 \mathrm{~min}$ ) and washed three times with saline. The multi-step procedure to prepare the haemolysate and the hydrolysate is summarized in fig. 1 .

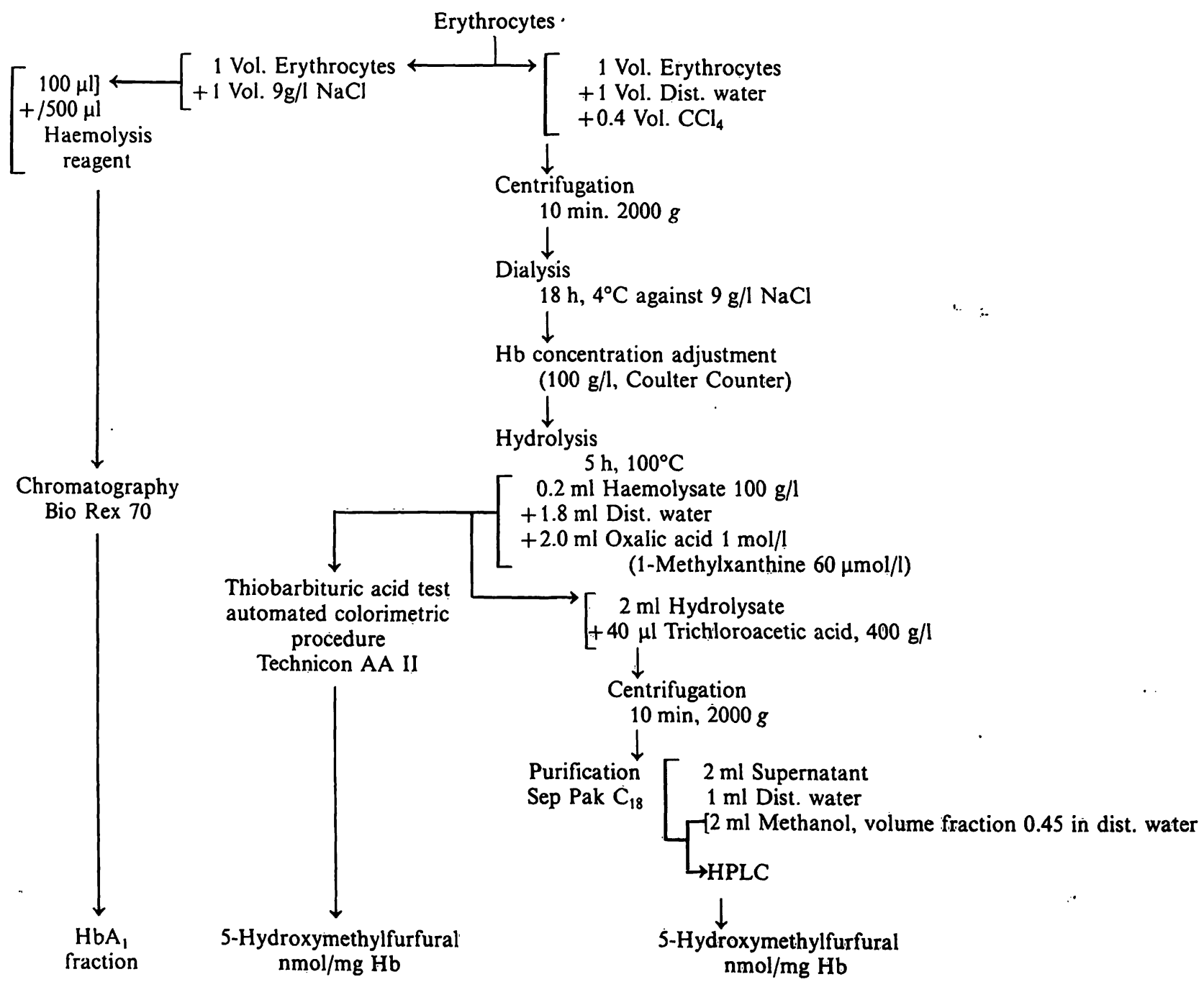

Fig. 1. Protocol followed for $\mathrm{HbA}_{1}$ determination using a BioRad column and for 5-hydroxymethylfurfural determination using the thiobarbituric acid method or HPLC method. 


\section{Ion-exchange method}

HbA, quantification was performed using cation exchange mini-columns purchased from BioRad (Orimbio, Paris, F). Chromatographic spearation was performed as described by the manufacturers during the two days following the blood collection. The temperature was in the range $20-22^{\circ} \mathrm{C}$. Results are expressed as $\mathrm{HbA}_{1}$ fraction of total haemoglobin.

\section{5-hydroxymethylfurfural derminations}

The hydrolysis procedure was performed by the Pecoraro technique (14). Briefly, the dialysed haemolysate diluted with $1.8 \mathrm{ml}$ distilled water was hydrolysed for 5 hours at $100^{\circ} \mathrm{C}$ with $2 \mathrm{ml}$ of $1 \mathrm{~mol} / 1$ oxalic acid, containing $60 \mu \mathrm{mol} / 11$-methylxanthine as internal standard for HPLC determination.

\section{Thiobarbituric acid test}

The glycosyl moiety was determined by an automated method using a Technicon Autoanalyser II (Domont, F), reagents and a procedure previously described (20). In order to prevent the effect of light during the development of the coloration, aluminium foil was put on the Technicon analyser. Results are expressed as nmol 5-hydroxymethylfurfural per $\mathrm{mg} \mathrm{Hb}$. The standard curve was obtained by dilution before assay of $2.3 \mathrm{mmol} / \mathrm{l} 5$-hydroxymethylfurfural stock solution (stored at $-1.8^{\circ} \mathrm{C}$ ) to cover the range $2.3-23 \mu \mathrm{mol} / 1$.

\section{HPLC determination}

The HPLC system consisted of a continuous constant flow pump generating a flow rate of $1.5 \mathrm{ml} / \mathrm{min}$, equipped with a loading sample injector valve $(20 \mu \mathrm{l}$ loop) and a LC-UV detector Pye Unicam (Philips, Bobigny, F) operated at $280 \mathrm{~nm}$. The sensitivity was set at 0.01 absorbance unit full scale. The HPLC column $(20 \mathrm{~cm} \times 4 \mathrm{~mm}$ I. D. $)$ was a Lichrosorb RP$18,7 \mu \mathrm{m}$. The chromatographic system was operated at room temperature. The mobile phase consisted of methanol-tetrahydrofuran-acetic acid-water $(6.2+0.3+1+93.5$ by volume). As previously described (21) the hydrolysates were purified on a Sep Pak C-18 cartridge. The standard curve was obtained by dilution of $1 \mathrm{ml}$ of diluted stock standard solution in $1 \mathrm{ml}$ of hydrolysis reagent containing the internal standard, followed by processing on a Sep Pak C.-18 cartridge. The volume of standard of biological sample injected into the HPLC apparatus was $20 \mu \mathrm{l}$.

\section{Results}

Analytical variables for 5-hydroxymethylfurfural determination

The internal standard (1-methylxanthine) added before hydrolysis for HPिLC determination did not give any.coloration with thiobarbituric acid.

In order to test the dialysis step, an increasing concentration of glucose was added to the haemolysate before hydrolysis. HPLC results show that the amount of 5-hydroxymethylfurfural increased after hydrolysis when the concentration of glucose increased. Thus the dialysis step appears to be essential for an accurate determination of 5-hydroxymethylfurfural released from glycated haemoglobin.
The more tedious step in the colorimetric method is the haemoglobin concentration adjustement. In order to investigate the necessity for this step, the amount of 5-hydroxymethylfurfural released by hydrolysis was determined by the thiobarbituric acid test and by the HPLC procedure for increased concentrations of haemoglobin. Figure 2 shows clearly that the 5hydroxymethylfurfural determination using the colorimetric method depends on the haemoglobin concentration. In contrast, when the HPLC procedure is used, the 5-hydroxymethylfurfural determination is stoichiometric.

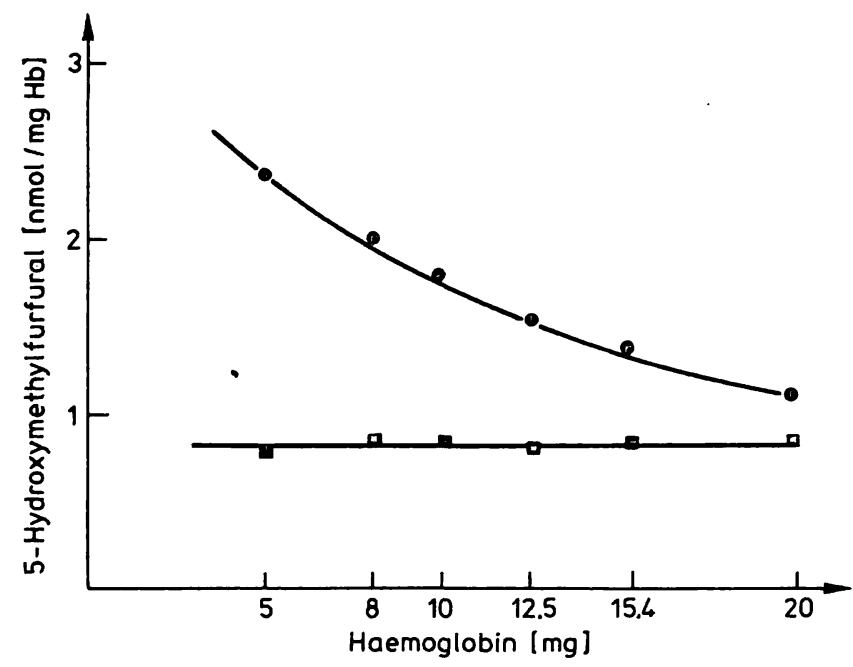

Fig. 2. Influence of haemoglobin concentration in the haemolysate on 5-hydroxymethylfurfural determination using the colorimetric thiobarbituric acid method (O-O) and the HPLC method $(\boldsymbol{\square}-\boldsymbol{\square})$ (the determinations were carried out on the same hydrolysates).

The Sep Pak C-18 cartridge purification of the haemolysate appears to be an improvement for an accurate determination of 5-hydroxymethylfurfural using the HPLC procedure as shown in figure 3 . The Sep Pak C-18 cartridges can be used three times if they are washed between each purification according to the procedure previously described (21).

\section{Comparison of methods}

\section{Precision}

The between-assay precision was determined for non diabetic subjects. The coefficient of variation (C.V.) for the cation exchange chromatographic method was $8.4 \%$ (22). C.V. for the semi-automated colorimetric method was $4.8 \%$ (20) and C.V. for the HPLC determination of 5-hydroxymethylfurfural was $4.5 \%$ (21). 

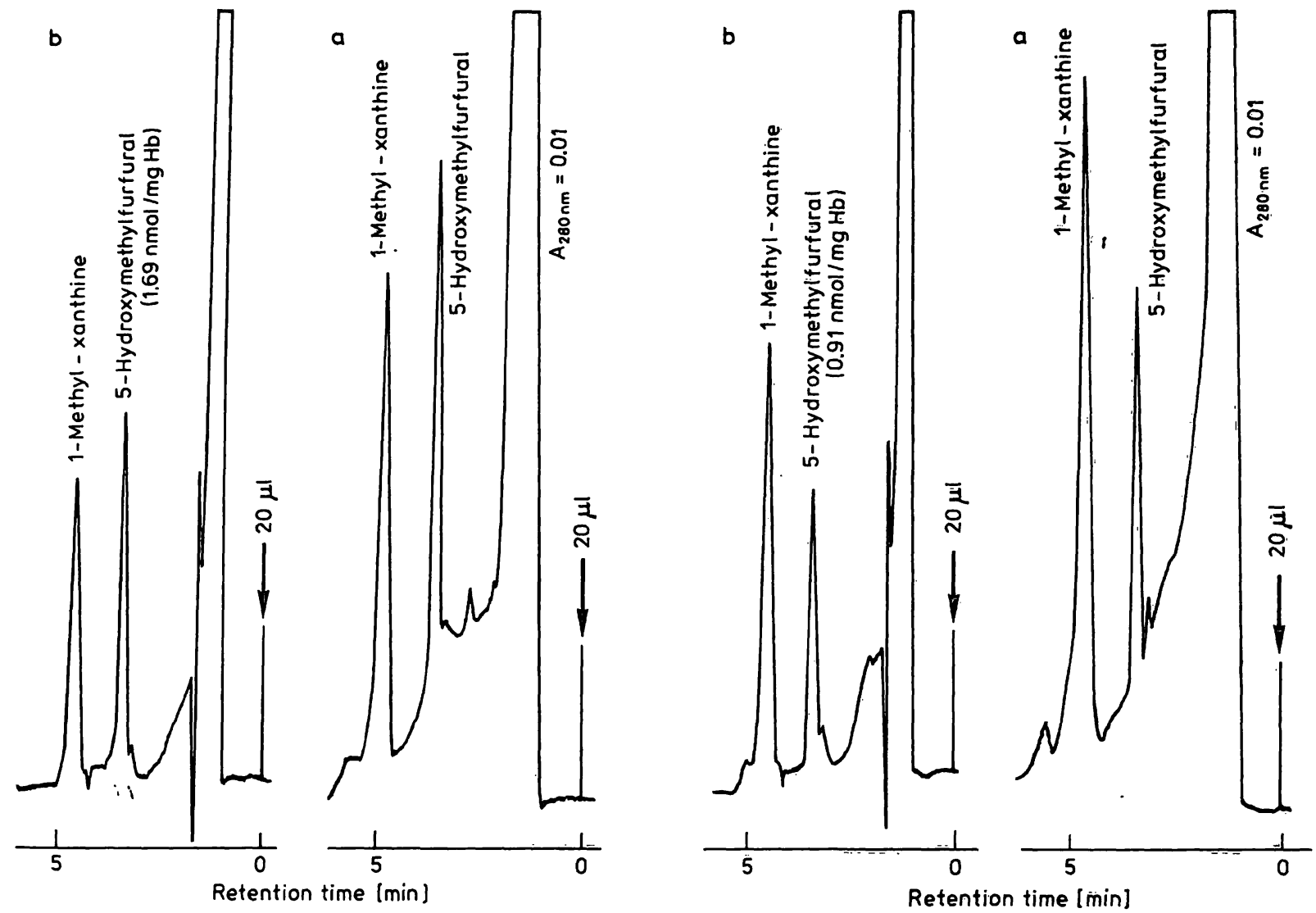

Fig. 3. Chromatograms of two haemolysates before (a) and after (b) Sep Pak C-18 cartridge purification. The concentrations of 5-hydroxymethylfurfural are indicated by brackets.

\section{Specificity}

Adduct formation with haemoglobin has been described for compounds other than glucose, such as carbamyl residues or acetaldehyde. Under such conditions, the specificity of the cation exchange chromatographic method was shown to be unreliable. In contrast, the colorimetric method is not affected by such a change (23). The specificity of the HPLC method has already been discussed in detail (21). The discrepancy between 5-hydroxymethylfurfural results obtained by the colorimetric or HPLC method, as shown in figure 2, 4 and 5, suggests the presence of a background colour absorbance in the colorimetric method.

\section{Clinical study}

The amount of $\mathrm{HbA}_{1}$ (expressed as fraction of total haemoglobin) or of carbohydrate bound to haemoglobin (5-hydroxymethylfurfural expressed in $\mathrm{nmol} /$ $\mathrm{mg} \mathrm{Hb}$ ) in control and diabetic subjects was determined by the three methods on the same samples. The results are represented in figure 4.

The values were:

- Ion-exchange method: $0.0643 \pm 0.0076(\mathrm{~m} \pm \mathrm{SD}$, $\mathrm{n}=27)$ for controls and $0.0923 \pm 0.0204(\mathrm{n}=$ 42) for diabetics.
- Thiobarbituric acid procedure: 5-hydroxymethylfurfural $1.74 \pm 0.17 \mathrm{nmol} / \mathrm{mg} \mathrm{Hb}$ for the control group and $2.26 \pm 0.47$ for the patient group.

- HPLC determination: 5-hydroxymethylfurfural $0.64 \pm 0.13 \mathrm{nmol} / \mathrm{mg} \mathrm{Hb}$ and $1.20 \pm 0.41$ for controls and diabetics respectively.

Using the three methods the differences between both groups were always significant $(p<0.001)$, the HPLC procedure having greatest significance. As can be seen from the scatter of the values in figure 4 the overlap between the control and the diabetic values was least with the HPLC method. Comparison of results from the colorimetric and HPLC methods for 5-hydroxymethylfurfural shows a systematic enhancement by the former method, equivalent to about $1.1 \mathrm{nmol} /$ $\mathrm{mg} \mathrm{Hb}$. Moreover if the diabetic and normal mean value ratios are compared, this ratio is higher (1.87) for HPLC method than for the cation exchange method (1.43) or the thiobarbituric acid test (1.30), suggesting that the HPLC method would be more useful in the management of diabetes mellitus. At least, it is worth noting that in normals the 5-hydroxymethylfurfural values $(0.64 \mathrm{nmol} / \mathrm{mg} \mathrm{Hb})$ are three times higher than 5-hydroxymethylfurfural values $(0.21 \mathrm{nmol} / \mathrm{mg}$ of protein) reported for glycated serum proteins using almost the same hy-drolysis procedure (20). These results are in agreement with the difference in the half life between serum proteins and haemoglobin. 


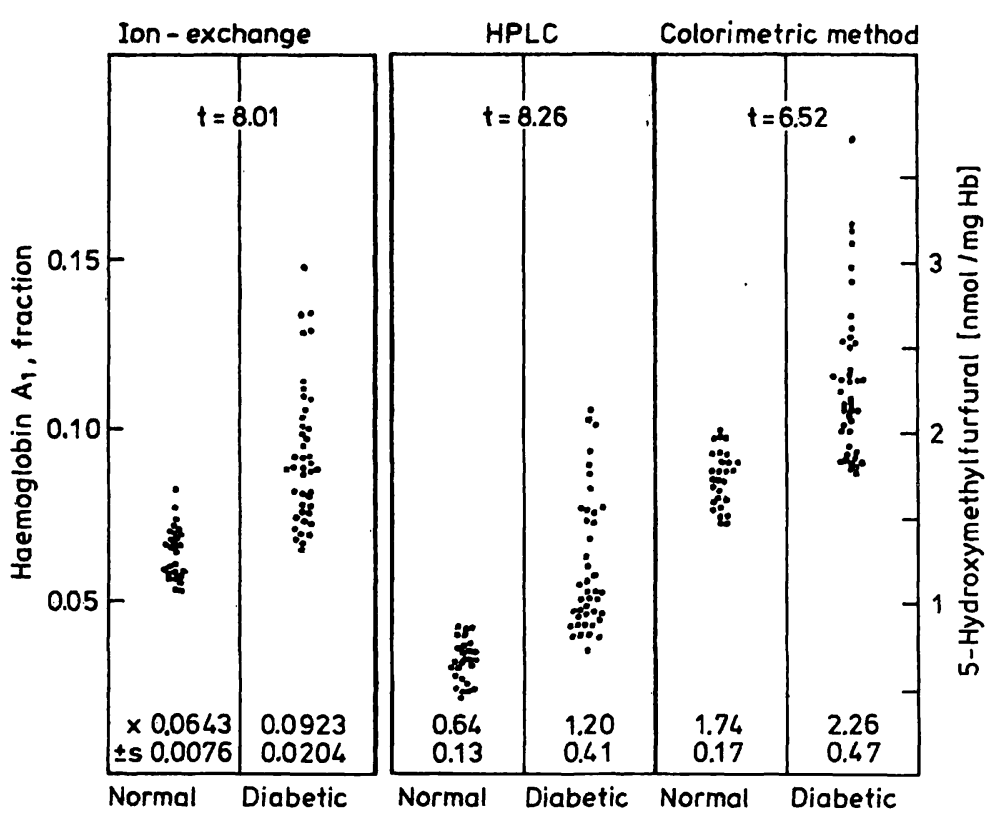

Fig. 4. Amount of $\mathrm{HbA}_{1}$ determined by the use of a BioRad column; and the amount of carbohydrate bound to haemoglobin as determined by the colorimetric thiobarbituric acid method and the 5-hydroxymethylfurfural HPLC method. In each case, results are shown for both control and diabetic subjects.

\section{Correlation studies}

The results obtained for control and diabetic subjects with the colorimetric method and with the HPLC method were correlated (fig. 5a). The results obtained with the BioRad columns and with HPLC method were also compared (fig. $5 \mathrm{~b}$ ). Results by all these methods correlated well, but the correlation between the ion exchange method and HPLC results was stronger $(r=0.88, p<0.001, y=0.044 x+0.038)$

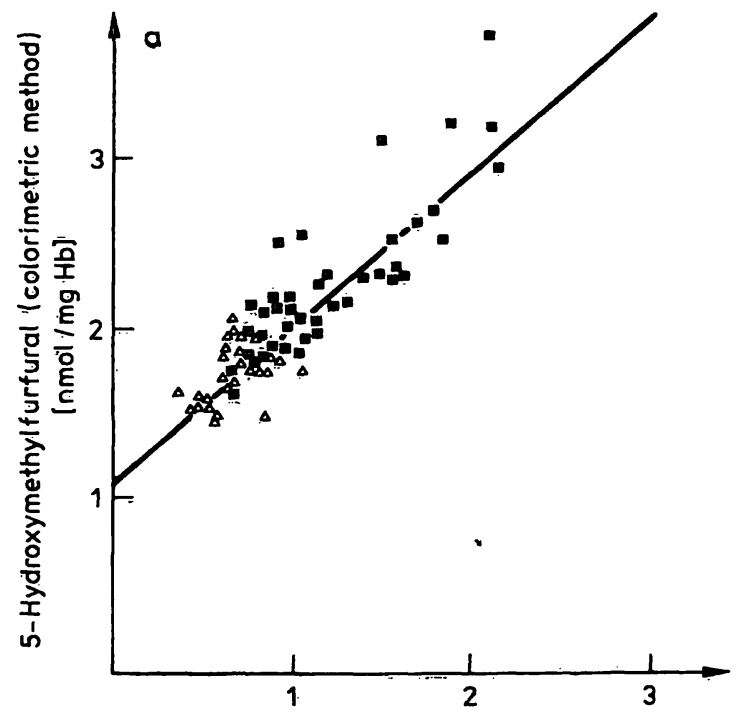

5-Hydroxymethylfurfural (HPLC) [nmol/mg Hob] than between the colorimetric method and HPLC $(r=0.86, p<0.001, y=0.93 x+1.14)$. The relative deviation from linearity may be due to differences in background absorbance caused by adjustment of the haemoglobin level for the colorimetric assay. For the same samples the linear regression results were $\mathrm{HbA}_{1}=0.041$ (5-HMF, TBA $)-0.003(\mathrm{r}=0.88$, $\mathrm{p}<0.001)$.

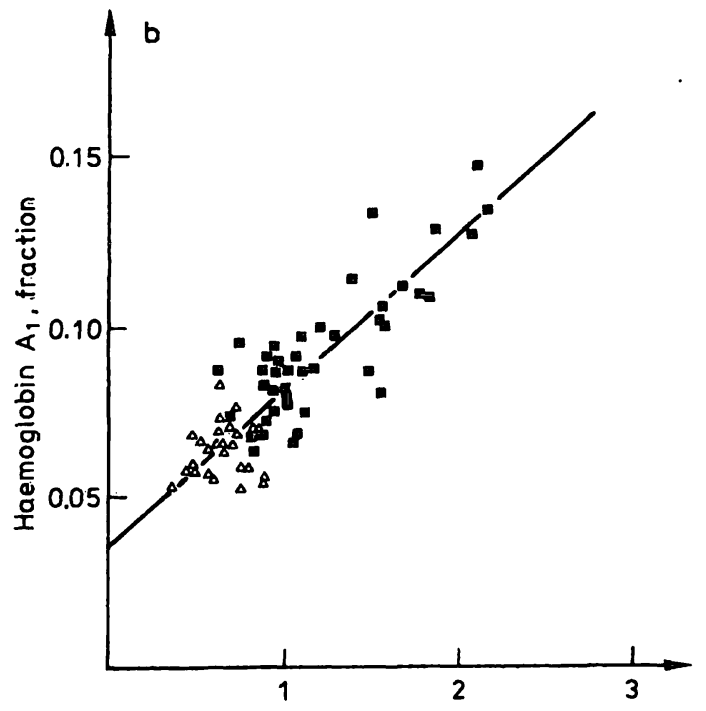

5-Hydroxymethylfurfural (HPLC) (nmol/mg Hb]

Fig. 5. Comparison of:

a) 5-hydroxymethylfurfural levels determined by the colorimetric thiobarbituric acid test and by HPLC in control ( $\triangle$ ) and diabetic ( $)$ subjects. $y=0.93 x+1.14 ; r=0.86$

b) $\mathrm{HbA}_{1}$ levels determined using a BioRad column and 5-hydroxymethylfurfural levels determined by HPLC in control $(\Delta)$ and diabetic $(\square)$ subjects. $y=0.044 x+0.038 ; x=0.88$ 


\section{Discussion}

High concentrations of glucose in blood may influence the colorimetric method $(20,24)$. The results reported here confirm that free glucose also gives rise to 5-hydroxymethylfurfural under the conditions used for the hydrolysis of glycated haemoglobin. Dialysis of haemolysates, as proposed here, or washing the blood cells, as proposed by Standefer (25), eliminated this interference.

It has been reported $(14,16,25)$ that the production of 5-hydroxymethylfurfural from haemoglobin may vary with the amount of haemoglobin in the hydrolysis mixture. Some of the absorbance measured in colorimetric assays may be due to non-specific colour absorbance contributed by the sample (26). Under the hydrolysis conditions reported here, the background colour absorbance is important and equivalent to $1.1 \mathrm{nmol} / \mathrm{mg} \mathrm{Hb}$. Our results show that not only the 5-hydroxymethylfurfural but also a coloured compound are released by oxalic hydrolysis of haemoglobin. This coloured compound is dialysable and gives an absorbance at $440 \mathrm{~nm}$. As shown in figure 2 , the lower the concentration of haemoglobin, the higher is this interference. In the colorimetric method the haemoglobin concentration must before be adjusted to a known value before hydrolysis. It is then assumed that this interference is the same for every sample. As the HPLC method is is stoichiometric and specific such an adjustement can be omitted.

The purification of biological samples is often necessary in HPLC procedures. Such a step permits a more accurate and precise determination of 5-hydroxymethylfurfural. Moreover, this step enhances the life of the column.

Comparing the time required to run the various assays, ion exchange chromatography is certainly the least time consuming, but it has many disadvantages $(8-12)$. The temperature is particularly crucial in obtaining satisfactory results with this method. The colorimetric procedure, especiälly when it is automated (18-20), seems more adapted for a great number of analyses. The equipment used for the HPLC procedure is of a type available in hospital laboratories and the accuracy in the determination of 5-hydroxymethylfurfural compensates for the time required to obtain results.

The HPLC procedure appears to be a convenient tool for determining the degree of glycation of proteins, such as haemoglobin. It should be easily adaptable to other proteins.

\section{Acknowledgements}

The authors wish to thank Pr. J.P. Bercoviçi for supplying the biological samples and Dr. F. L. Berthou for valuable discussion of the manuscript.

\section{References}

1. Trivelli, L. A., Ranney, H. M. \& Lai, H. (1971) N. Engl. J. Med. 284, 353-357.

2. Gabbay, K.M., Hasty, K., Breslow, J. L., Ellison, R. C., Bunn, H. G. \& Gallop, P. M. (1977) J. Clin. Endocrinol. Metab. 44, 859-864.

3. Bunn, H. F., Gabbay, K. M. \& Gallop, P. M. (1978) Science $200,21-27$.

4. Mayer, T. K. \& Freedman, Z. R. (1983) Clin. Chim. Acta $127,147-184$.

5. Kynoch, P. A. M. \& Lehmann, H. (1977) Lancet II, 16.

6. Welch, S. G. \& Boucher, B.J. (1978) Diabetologia 14, 209-211.

7. Abraham, E. C., Huff, T. A., Cope, N. D., Wilson, J. B. Jr., Bransome, E.D. Jr. \& Huisman, T. H.J. (1978) Diabetes $27,931-937$

8. Simon, M. \& Eissler, J. (1980) Diabetes 29, 467-474.

9. Schellekens, A.P. M., Sanders, G.T.B., Thornton, W. \& Van Groenestein, T. (1981) Clin. Chem. 27, 94-99.

10. Compagnucci, P., Cartechini, M. G., Bolli, G., De Feo, P., Santeusanio, F. \& Brunetti, P. (1981) Diabetes 30, $607-612$.

11. Little, R.R., England, J.D., Wiedmeyer, H.M. \& Goldstein, D. E. (1983). Clin. Chem. 29, 1113-1115.

12. Aleyassine, H., Gardiner, R. J., Blankstein, L. A. \& Dempsey, M. E. (1981) Clin. Chem. 27, 474-477.

13. Flückiger, R. \& Winterhalter, K.H. (1976) FEBS Lett. 71, $356-360$.

14. Pecoraro, R.E., Graf, R.J., Halter, J.B., Beiter, H. \& Porte, D. Jr. (1979) Diabetes 28, 1120-1125.

15. Saibene, V., Brembilla, L., Bertoletti, A., Bolognani, L. \& Pozza, G. (1979) Clin. Chim. Acta 93, 199-205.

16. Parker, K.M., England, J.D., da Costa, J., Hess, R. \& Goldstein, D. E. (1981) Clin. Chem. 27, 669-672.

17. Subramanian, C. V., Radhakrishnamurthy, B. \& Berenson, G.S. (1980) Clin. Chem. 26, 1683-1687.

18. Ross, I.S. \& Gibson, P. F. (1979) Clin. Chim. Acta 98, $53-59$.

19. Burrin, J.M., Worth, R., Ashworth, L. A., Currie, S. \& Alberti, K. G. M. M. (1980) Clin. Chim. Acta 106, 45-50.

20. Ménez, J. F., Meskar, A., Lucas, D., Darragon, T., Floch, H. H. \& Bardou, L. G. (1981) Clin. Chem. 27. 1947-1948.

21. Ménez, J.F., Berthou, F. L., Meskar, A., Picart, D., Le Bras, R. \& Bardou, L. G. (1984) J. Chromatogr. 297, $339-350$.

22. Rowe, D.J.F. \& Goodland, F. C. (1984) Clin. Chem. 30, $156-157$.

23. L'Emeillat, M., Ménez, J.F., Meskar, A., Kaiser, J.M. \& Bardou, L. G. (1983) Biologie Prospective, 5e Coll. Int. Pont à Mousson, Masson éd., pp. 599-602.

24. Kennedy, A. L., Mehl, T. D. \& Merimee, T.J. (1980) Diabetes $29,413-415$.

25. Standefer, J.C. \& Eaton, R.P. (1983) Clin. Chem. 29, $135-140$

26. Bunn, H.F. (1981) Diạbetes $30,613=617$.

Jean-François Ménez
Laboratoire de Biochimie A
Hôpital A. Morvan
F-29279 Brest Cedex .;

